\title{
The Impact of the COVID-19 Lockdown on the Quality of Life in Chronic Neurological Diseases: The Results of a COVQoL-CND Study
}

\author{
Sevki Sahin ${ }^{a}$ Sibel Karsidag ${ }^{a} \quad$ Nilgun Cinar $^{a} \quad$ Miruna Florentina Ates ${ }^{a}$ \\ Serkan Demir ${ }^{b}$ Fettah Eren $^{c}$ Abdurrahman Neyald Aysin Kisabay Ak ${ }^{\mathrm{e}}$ \\ Ayse Bora Tokcaer ${ }^{f}$ Esra Erkoc Ataoglu ${ }^{f}$ Seda Nur Akkaya ${ }^{f}$ Esra Aciman Demirelg \\ Filiz Koc $^{\text {h }}$ Serefnur Ozturk ${ }^{c}$ Yasemin Ekmekyapar Firat ${ }^{i}$ Tugba Okluoglu $^{j}$ \\ Erdem Togrolk $^{k}$ Ali Kemal Erdemoglul Nesrin Ergin ${ }^{m}$ Refah Sayin ${ }^{n}$ \\ Aysegul Demir $^{\circ}$ Sueda Ecem Yilmaz ${ }^{c}$
}

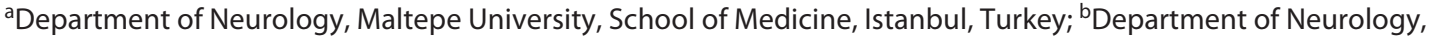
University of Health Sciences, Sancaktepe Research and Training Hospital, Istanbul, Turkey; 'Department of Neurology, Selcuk University, School of Medicine, Konya, Turkey; ${ }^{d}$ Dr. Ersin Arslan Research and Training Hospital, Gaziantep,

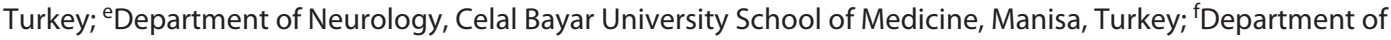
Neurology, Gazi University, School of Medicine, Ankara, Turkey; ${ }^{9}$ Department of Neurology, Bülent Ecevit University Faculty of Medicine, Zonguldak, Turkey; ' Department of Neurology, Cukurova University, Faculty of Medicine, Adana, Turkey; 'Department of Neurology, SANKO University, School of Medicine, Gaziantep, Turkey; jDepartment of Neurology, Health Sciences University, Istanbul Education Research Hospital, Istanbul, Turkey; ${ }^{\text {kDepartment }}$ of Neurology, University of Health Science, Hamidiye School of Medicine, Sultan Abdulhamid Han Research and Training Hospital, Istanbul, Turkey; 'Erdemoglu Neurology and Pain Clinic, Ankara, Turkey; 'mepartment of Neurology, Pamukkale University, Medical Faculty, Denizli, Turkey; ${ }^{\mathrm{n}}$ Department of Neurology, Ufuk University, School of Medicine, Ankara, Turkey; ${ }^{\circ}$ Department of Neurology, Konya City Hospital, Konya, Turkey
\end{abstract}

\section{Keywords}

COVID-19 · Lockdown · Posttraumatic stress · Quality of life · Neurological diseases

\footnotetext{
Abstract

Background: Coronavirus disease 2019 (COVID-19) pandemic and lockdown period may induce an impairment in quality of life (QoL), disruption in treatment (DIT), and posttraumatic stress disorder (PTSD) in chronic neurological diseases (CNDs). To reach this information, a multicenter, crosssectional study (COVQoL-CND) was planned. Parkinson's dis-
}

ease (PD), headache (HA), multiple sclerosis (MS), epilepsy (EP), polyneuropathy (PNP), and cerebrovascular disease (CVD) were selected as the CND. Methods: The COVQoLCND study includes demographic data, the World Health Organization Quality of Life short form (WHOQOL-BREF), and Impact of Event Scale-Revised (IES-R) forms. Results: The mean age of a total of 577 patients was $49 \pm 17$ (19-87 years), and the ratio of female/male was 352/225. The mean age of patients with PD, HA, MS, EP, PNP, and CVD were $65 \pm 11,39$ $\pm 12,38 \pm 10,47 \pm 17,61 \pm 12$, and $60 \pm 15$ years, respectively. The IES-R scores were found to be higher in the younger group, those with comorbid disease, contacted with CO- karger@karger.com www.karger.com/ene
(C) 2021 S. Karger AG, Basel 
VID-19 patients, or diagnosed with COVID-19. In the group with a high IES-R score, the rate of DIT was found to be high. IES-R scores were negatively correlated with QoL. IES-R total scores were found highest in the CVD group and lowest in the PD group. The ratio of DIT was found highest in the PNP group and the lowest in the EP group. Contact with COVID-19 patients was high in the EP and HA group. Conclusions: The results of the COVQoL-CND study showed that lockdown causes posttraumatic stress and deterioration in the QoL in CND.

(C) 2021 S. Karger AG, Basel

\section{Introduction}

The coronavirus disease 2019 (COVID-19) outbreak, which originated in Wuhan, China, in December 2019, spread all over the world in a short time [1]. It spread rapidly in more than 200 countries and was declared a pandemic by the World Health Organization on January 30, 2020 [2]. The International Virus Taxonomy Committee named the virus-related disease "severe acute respiratory syndrome coronavirus 2 (SARS-CoV-2)" [3].

Prior to the current COVID-19 pandemic, the human race has witnessed at least 5 outbreaks in the current century: H1N1 in 2009, polio in 2014, Ebola in 2016, Zika in 2016, and Ebola in 2019. Historically, precautions were taken against the severe acute respiratory syndrome (SARS) outbreak - including quarantine in China and Canada in 2003, and it was brought under control within 8 months [4-6]. In 2014, 3 West African countries affected by the Ebola epidemic (Guinea, Liberia, and Sierra Leone) instituted and enforced a mass quarantine [7].

It has been reported that during past epidemics, depression, anxiety, and substance abuse increased. In addition, high mortality rates combined with the fear of contact with infected people may adversely affect mental health $[6,8]$. As a result, moderate to severe posttraumatic stress symptoms were reported in certain populations during quarantine, especially among women [8].

To our knowledge, the COVID-19 pandemic has resulted in the largest and most restrictive lockdown period the world has so far seen. Since December 2019, this has resulted in a serious evaluation of the quality of life (QoL) and of the psychosocial and mental effects of quarantine [4].

Turkey confirmed its first case of COVID-19 on March 11, 2020. Between March and May, people over 65 years as well as those under 20 years were under complete lockdown over almost the whole country. Enforced quaran- tine restrictions were relaxed on the first weekend of June, and freer rights of movement combined with strict rules of hygiene (wearing a mask, hand cleaning, and social distancing) were instituted after August. Unfortunately, due to the increase in the number of cases, quarantine rules, including a lockdown, were reinstituted on November 1 , 2020.

In scientific terminology, the word "lockdown" describes "restrictive mass quarantine." Quarantine is often an unpleasant experience. In addition to financial difficulties, a feeling of restriction, separation from family and friends, and an atmosphere of uncertainty about the illness can result in psychological problems $[9,10]$. Therefore, it is necessary that new strategies be developed to deal with these problems [11].

We aimed to evaluate the QoL, posttraumatic stress disorder (PTSD), and disruption in treatment (DIT) of patients with chronic neurological diseases (CNDs) in the lockdown period which, in Turkey, started in March 2020. The CND samples, which included Parkinson's disease (PD), headache (HA), multiple sclerosis (MS), epilepsy (EP), polyneuropathy (PNP), and cerebrovascular disease (CVD) all common in neurology outpatient clinics, were taken as a target group. The results will help us to evaluate our patients' neuropsychological problems during the lockdown period and to develop appropriate strategies for dealing with them.

\section{Materials and Methods}

Study Design and Selection of Patients

A multicenter, cross-sectional study (COVQoL-CND) was organized and commenced on June 1,2019. The questionnaire forms were filled out by the patients after being briefed by a neurologist.

Data were obtained from different hospitals located in 43 Turkish cities. Patients who had been followed up for at least 1 year in an outpatient clinic were randomly enrolled in the study.

Patients were also questioned about demographic findings and medical history including age, gender, city of residence during the lockdown period, lifestyle (living alone or not alone), comorbid diseases, smoking and alcohol consumption habits, DIT, and whether they had been diagnosed as infected by COVID-19 or had been in contact with a COVID-19 patient. The study was approved by the local Ethics Committee after receiving the authorization of the Ministry of Health.

\section{Assessment of Patients}

Impact of Event Scale - Revised

Impact of Event Scale - Revised (IES-R) was used to identify the presence of PTSD. IES-R consists of 22 items and it evaluates according to a 5-point Likert scale (0: not at all, 4: extremely). The total score of the IES-R ranges from 0 to 88 . The total score is proportional to the severity of the psychological condition. The IES-R 

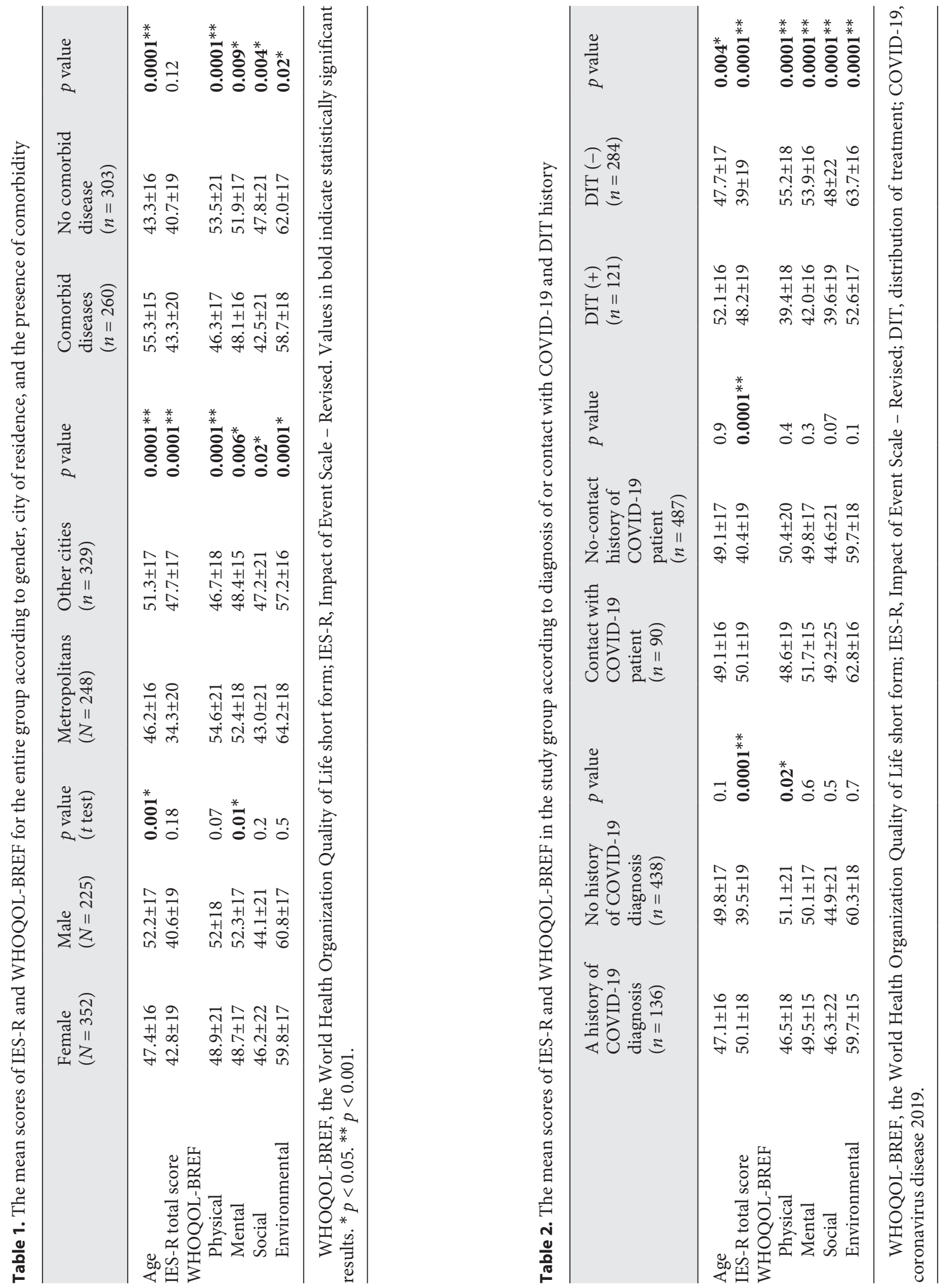
scale has 3 subscales labeled intrusion, hyperarousal, and avoidance [12]. Several cutoff values of the IES-R scale have been reported, ranging from 22 to 44 in some studies which included cases with substance abuse disorders, survivors of war, and survivors of arsenic poisoning [13-15].

It was validated in Turkish by Çorapçığlu et al. [16]. We used 30 as a cutoff value which they had suggested for the Turkish population. The higher scores show more severe posttraumatic stress. Scoring over 30 was considered as a cutoff point for a "probable PTSD case." Probable cases were named PTSD $(+)$. PTSD $(+)$ and PTSD (-) groups were compared with the other parameters. Furthermore, Vanaken et al. [17] found that IES-R is a valid and reliable test in the evaluation of PTSD associated with COVID-19.

The World Health Organization Quality of Life Scale

The World Health Organization Quality of Life (WHOQOLBREF) scale was used to evaluate the QoL [18]. This scale was developed by the World Health Organization and the Turkish version was validated by Eser et al. [19]. It has physical, mental, social, and environmental subdomains and consists of 26 questions. Each subdomain expresses the QoL in its field independently from each other.

The subdomain scores are calculated between 4 and 20 and converted to a $0-100$ scale.

$\frac{\text { Actual raw score }- \text { Lowest possible raw score }}{\text { Possible raw score }} \times 100$.

Higher scores predict higher QoL.

\section{Statistical Analysis}

Statistical analysis was performed using SPSS version 16.0 (IBM, Chicago, IL, USA). Descriptive statistics for demographic data were calculated. The results were explained as the mean \pm standard deviation (SD) for quantitative data and percentage for categorical data. Differences in quantitative data distributions between the 2 groups were tested by a Student's $t$-test for normally distributed data and a Wilcoxon rank-sum test or Kruskal-Wallis test for nonnormal distributed data. A one-way ANOVA test was used for multiple group analysis. To investigate the correlation of IES-R scores with other parametric factors, we used the Pearson correlation coefficient. Multivariate analysis was performed to explain the factors associated with IES-R. A multiple linear regression analysis was used to predict the factors affecting PTSD. A $p$ value $<0.05$ was accepted as statistically significant.

\section{Results}

Five hundred and seventy-seven patients were enrolled in the study. Distribution of CND were $98 \mathrm{PD}, 158$ HA, $126 \mathrm{MS}, 67 \mathrm{EP}, 60 \mathrm{PNP}$, and $68 \mathrm{CVD}$.

The mean age of the patients was $49 \pm 17$ years (range: 19-87 years). The mean age of men was found to be higher than that of women. The study group consisted of 352 women and 225 men. Two hundred and forty-eight patients admitted to the study resided in large metropolitan cities (Istanbul/Ankara/Izmir) and 329 lived in other cities of Turkey.

The percentage of "singles" was 7\%, and that of those living with relatives or caregivers, $93 \%$. The ratio of comorbid diseases was found to be $46 \%$ (hypertension $29 \%$, heart disease $13 \%$, diabetes mellitus $10 \%$, psychiatric illness $5 \%$, hypothyroidism $2.8 \%$, chronic obstructive pulmonary disease $2.3 \%$, cancer $0.7 \%$, and chronic renal failure $0.5 \%)$. The mean age of patients with comorbid disease was higher than that of the others.

Nineteen percent of the patients were habitual smokers and $4 \%$ of patients had a history of alcoholism. Fifteen percent of the patients reported that they had been diagnosed with COVID-19, while a further $24 \%$ of patients had a history of contact with COVID-19 patients (total ratio of diagnosed with COVID-19 or contact with COVID-19 patients was 39\%).

The mean scores of subdomains in IES-R were as follows. Intrusion: $14 \pm 8$, avoidance: $16.8 \pm 7$, and hyperarousal: $10.8 \pm 5$. The ratio of probable PTSD (IES-R $\geq$ 30 ) was found to be $32 \%$. There was no statistical difference between men and women according to IES-R score. The mean of the total IES-R score was lower in patients residing in metropolitan areas.

The mean scores of the subscales for WHOQOL-BREF were as follows, physical score: $50 \pm 20$, mental score: 50 \pm 17 , social score: $45 \pm 21$, and environmental score: $60 \pm$ 17. There was no difference between men and women in terms of WHOQOL-BREF scores except for the mental subscale score. The WHOQOL-BREF mental subscore was found to be lower in women than men. The mean score of physical, mental, and social subscales of WHOQOL-BREF was higher in patients residing in metropolitan areas and having no comorbid disease. The distribution of mean scores of IES-R and WHOQOL-BREF for the whole group, according to gender, city of residence, and the existence of comorbidities, is shown in Table 1.

The mean age of patients who have reported DIT was found to be higher than the others. The mean of the IES$\mathrm{R}$ total score was higher in those patients diagnosed with COVID-19 and/or having had contact with COVID-19 patients and who had a DIT history. The mean scores of all subscales in WHOQOL-BREF were lower in DIT (+) patients. The distribution of mean scores of IES-R and WHOQOL-BREF for the study group according to COVID-19 diagnosis and contact with COVID-19 patients and DIT history is shown in Table 2.

The mean age of the patients was younger, and the mean scores of WHOQOL-BREF subscales were found lower in the probable PTSD (+) group. The diagnosis of 
Table 3. Comparison of the parameters of patients according to the existence of probable posttraumatic stress disorder

\begin{tabular}{|c|c|c|c|}
\hline & $\begin{array}{l}\operatorname{PTSD}(+) \\
(n=390)\end{array}$ & $\begin{array}{l}\text { PTSD }(-) \\
(n=184)\end{array}$ & $p$ value \\
\hline Age, years & $48 \pm 16$ & $51 \pm 17$ & $0.02^{*}$ \\
\hline Gender, female/male & $240 / 150$ & $109 / 75$ & 0.3 \\
\hline \multicolumn{4}{|l|}{ WHOQOL-BREF } \\
\hline Physical & $45.3 \pm 18$ & $60.5 \pm 20$ & $0.0001^{* *}$ \\
\hline Mental & $46.1 \pm 15$ & $58.7 \pm 17$ & $0.0001^{* *}$ \\
\hline Social & $42 \pm 20$ & $51 \pm 24$ & $0.0001^{* *}$ \\
\hline Environmental & $56 \pm 16$ & $68 \pm 17$ & $0.0001^{* *}$ \\
\hline \multicolumn{4}{|l|}{ IES-R } \\
\hline Intrusion & $18.6 \pm 5$ & $4.8 \pm 3$ & $0.0001^{* *}$ \\
\hline Avoidance & $20.6 \pm 4$ & $8.9 \pm 3$ & $0.0001^{* *}$ \\
\hline Hyperarousal & $13.9 \pm 4$ & $4.2 \pm 3$ & $0.0001^{* *}$ \\
\hline Contact with COVID-19 patient, $\%$ & 29 & 12 & $0.0001^{* *}$ \\
\hline COVID-19 diagnosis, $\%$ & 19 & 9 & $0.002^{*}$ \\
\hline Comorbid diseases, $\%$ & 47 & 44 & 0.2 \\
\hline DIT, $\%$ & 36 & 22 & $0.001^{*}$ \\
\hline
\end{tabular}

PTSD (+): IES-R $\geq 30$, PTSD (-): IES-R <30; DIT, disruption of treatment; PTSD, posttraumatic stress disorder; WHOQOL-BREF, the World Health Organization Quality of Life short form; IES-R, Impact of Event Scale - Revised; COVID-19, coronavirus disease 2019. ${ }^{*} p<0.05$. ${ }^{* *} p<0.001$.
COVID-19 and contact with COVID-19 patients were more frequent in the PTSD (+) group. The DIT ratio was higher in the probable PTSD group (Table 3 ).

Thirty-two patients stated that there was a DIT. Comorbid diseases were found more frequently in CVD, PNP, and PD groups than the other groups. The history of contact with COVID-19 patients and the diagnosis of COVID-19 were more frequent in the EP and HA groups and both of them were rarer in the PD group.

DIT was reported more frequently in PNP and CVD groups. Patients have reported the reasons for DIT in the PNP group as follows: postponed intravenous immunoglobulin treatment by the hospital ( $n: 16)$ and being unable to get gabapentin/pregabalin treatment from the pharmacy ( $n: 22)$. In the CVD group, 12 patients stated that their warfarin levels could not be measured and 26 patients reported delays in their physical rehabilitation program. All patients in the PD group cited the loss of communication with the neurologist who made drug dose adjustments as the cause of DIT. In the HA group, 20 patients cited a fear of going to the emergency ward if suffering a migraine attack, and 22 patients cited not being able to get their medication from the pharmacy as the reason for DIT. Reported as the cause of DIT, 11 MS patients themselves discontinued their disease-modifying therapy without consulting their doctor, as they feared it would make it easier to get infected with COVID-19. Fourteen patients with MS stated that the parenteral disease-modifying therapy was postponed by the hospital where they were being treated. Three patients reported being afraid of visiting the emergency ward despite having had a seizure, and 4 patients reported having problems accessing their medication as the cause of DIT (Fig. 1).

All subscales of WHOQOL-BREF scores were lower when compared to other groups in the PNP group. The social subscale score was the lowest in the PD group. Although similar values were found among other disease groups, the lowest mean IES-R score was found in the PD group (Table 4).

A negative correlation was found between WHOQOLBREF subscales and IES-R scores. In the multiple linear regression analysis, the significant predictors of high IES$\mathrm{R}$ scores (posttraumatic stress) were found as residing in the metropolitan, type of CND, the physical subscale score of WHOQOL-BREF, age, and history of contact with COVID-19 patients.

\section{Discussion}

COVID-19 is a highly contagious disease and therefore social isolation is crucial to prevent spreading [20]. In our country, a lockdown particularly affected individuals over the age of 65 years from the beginning of the 
Table 4. Comparison of the parameters of patients according to chronic neurological disease

\begin{tabular}{|c|c|c|c|c|c|c|c|}
\hline & $\mathrm{PD}(n=98)$ & $\mathrm{HA}(n=158)$ & $\operatorname{MS}(n=126)$ & $\mathrm{EP}(n=67)$ & $\operatorname{PNP}(n=60)$ & $\operatorname{CVD}(n=68)$ & $p$ value \\
\hline Age & $65 \pm 11^{\mathrm{a}}$ & $39 \pm 12^{b}$ & $38 \pm 10^{\mathrm{b}}$ & $47 \pm 17^{\mathrm{c}}$ & $61 \pm 12^{\mathrm{a}, \mathrm{d}}$ & $60 \pm 15^{\mathrm{d}}$ & $0.0001^{* *}$ \\
\hline Gender (F/M) & $46 / 52^{\mathrm{a}}$ & $124 / 34^{\mathrm{c}}$ & $81 / 45^{\mathrm{b}}$ & $25 / 42^{\mathrm{a}}$ & $36 / 24^{a, b, c}$ & $40 / 28^{a, b, c}$ & $0.0001^{* *}$ \\
\hline Comorbid diseases, $\%$ & $61^{\mathrm{a}}$ & $36^{\mathrm{b}}$ & $20^{c}$ & $45^{\mathrm{a}, \mathrm{b}}$ & $70^{\mathrm{a}}$ & $79^{\mathrm{a}}$ & $0.0001^{* *}$ \\
\hline Contact with COVID-19 patient, \% & $7^{\mathrm{a}}$ & $31^{\mathrm{b}}$ & $19^{c}$ & $40^{\mathrm{b}}$ & $17^{\mathrm{a}, \mathrm{b}, \mathrm{c}}$ & $29^{b, c}$ & $0.0001^{* *}$ \\
\hline Diagnosis of COVID-19, \% & $5^{a}$ & $19^{\mathrm{b}}$ & $15^{\mathrm{b}}$ & $33^{c}$ & $13^{\mathrm{a}, \mathrm{b}}$ & $9^{\mathrm{ab}}$ & $0.001^{* *}$ \\
\hline Physical & $48 \pm 20^{\mathrm{a}}$ & $49 \pm 17^{\mathrm{a}}$ & $59 \pm 23^{b}$ & $55 \pm 19^{a, b}$ & $36 \pm 14^{c}$ & $44 \pm 14^{\mathrm{c}}$ & $0.0001^{* *}$ \\
\hline Mental & $51 \pm 1$ & $48 \pm 15$ & $55 \pm 19$ & $55 \pm 16$ & $43 \pm 16$ & $45 \pm 13$ & $0.001^{*}$ \\
\hline Social & $39 \pm 21$ & $45 \pm 21$ & $51 \pm 24$ & $48 \pm 23$ & $41 \pm 19$ & $44 \pm 17$ & $0.002^{*}$ \\
\hline Environmental & $66 \pm 16$ & $62 \pm 16$ & $61 \pm 19$ & $63 \pm 16$ & $46 \pm 13$ & $54 \pm 14$ & $0.0001^{* *}$ \\
\hline IES-R total score & $25 \pm 16^{\mathrm{a}}$ & $46 \pm 18^{b}$ & $37 \pm 18^{c}$ & $48 \pm 16^{b}$ & $49 \pm 18^{b}$ & $53 \pm 15^{b}$ & $0.0001^{* *}$ \\
\hline Intrusion & $8 \pm 6$ & $15.8 \pm 7$ & $12 \pm 7$ & $16.7 \pm 7$ & $17 \pm 7$ & $19 \pm 6$ & 0.0001 \\
\hline
\end{tabular}

WHOQOL-BREF, the World Health Organization Quality of Life short form; IES-R, Impact of Event Scale - Revised; DIT, distribution of treatment; COVID-19, coronavirus disease 2019; PD, Parkinson's disease; HA, headache; MS, multiple sclerosis; EP, epilepsy; PNP, polyneuropathy; CVD, cerebrovascular disease. ${ }^{*} p<0.05 .{ }^{* *} p<0.001 .{ }^{a-d} p<0.05$, data were analyzed for various chronic neurological diseases by variance ANOVA with post hoc Fisher's least significant difference (LSD) tests.

Fig. 1. The causes of DIT. DIT, disruption of treatment; DMT, disease-modifying therapy, INR, international normalized ratio; IVIG, intravenous immunoglobulin.

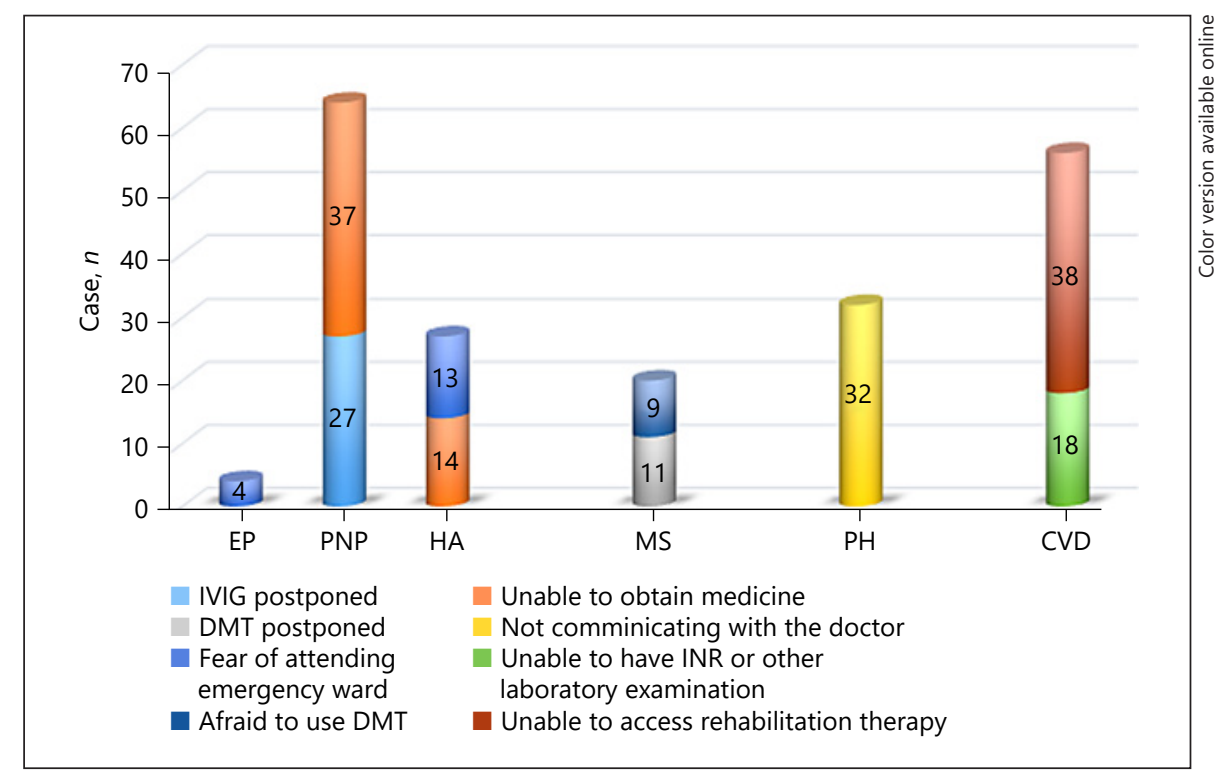

epidemic. In the PD group, where the most common group of patients is over the age of 65 , the rate of contact with COVID-19 patients and diagnosed COVID-19 was found to be the lowest. This finding indicates the protective effectiveness of the COVID-19 lockdown.

Severe country-wide social isolation programs can create anxiety, distress, loneliness, and loss of control. In addition, misperceptions transmitted by social media, negative economic and social effects, and the inability to access basic needs may further increase the psychological effects $[6,21,22]$. Despite there being no significant difference among the disease groups according to WHOQOL-BREFs physical, mental, and environmental scores, the social subscale was found to be the lowest among PD 
sufferers who because of advanced age, were affected by lockdown more than were other groups. This finding suggests that the lockdown particularly affects the social field, while preserving other aspects of one's QoL, as expected for PD cases. In previous studies, it has been suggested that epidemics of infection may trigger anxiety, fear, and other negative psychological problems and that this may have long-term consequences [23-25].

Most of the studies of the psychological impact of the current epidemic have been done in China. The study of Zhang and Ma [26] showed a mild PTSD with a ratio of $7.6 \%$ in participants living in Jinzhou that was not under "lockdown" and was 1,700 km distant from Wuhan. Some authors ascribed the relatively low stress ratio to the fact that people were not yet fully aware of the seriousness of the illness.

Wang et al. [27] planned a general population study of the first 2 weeks of the outbreak. The $53.8 \%$ of the participants reported negative psychological effects $(16.5 \%$ depression, $8.5 \%$ PTSD, and $28.8 \%$ anxiety). It was also found that women suffered more from psychological effects than did men in the same study. In our study, the ratio of PTSD was found to be higher than made by Zhang and Wang. One reason for the high rate of PTSD during our study is that we studied a special group (people with CND), and another reason may be that awareness of the disease had increased at the beginning of our study.

Losada-Baltar et al. [28] in their study of 1,310 subjects in Spain observed high levels of stress and loneliness among young adults and women. In our study, no difference in stress was observed between men and women. However, women had a lower WHOQOL-BREF mental subscore than men. Although it is not reflected in the stress situation, we can say that psychologically, the QoL is more affected in women.

It was noted that the most affected group was young adults in the 18-30 year age-group who are still being educated or are working in the studies. This group has been reported to be the most psychologically vulnerable group in such lockdowns. Young adults affected by unconfirmed information on the Internet and social media platforms may be more prone to stress $[29,30]$. The level of stress was found to be lower in the advanced age-group under total lockdown but higher in the youth under partial lockdown. This situation suggests that the protective effect of the disease lockdown creates trust and reduces stress.

In a study from Italy, the effect of forced lockdown on QoL in 2,251 people from general population was evaluated online with WHOQOL-BREF. Although $6.4 \%$ of participants had a history of contacted and/or diagnosed with COVID-19, worsening of psychological, physical, and environmental domains of QoL during the pandemic was reported for all subjects [31]. Our study was also conducted during the same lockdown period. Total ratio of diagnosis and/or contact with COVID-19 was found $39 \%$. All subdomains of QoL in those patients have been found more affected than the others. This might be an expected result for our study group, which consists of middle-aged and older patients who already have CNDs.

People with serious comorbidities have been reported as feeling anxiety, nervousness, excessive stress, and/or anger during the COVID-19 outbreak [32-34]. In our study, the stress rate was found to be similar in patients with and without comorbid diseases. However, the main point is that the QoL was found to be low in the group with comorbid diseases. This result indicates that priority should be given to those patients with CNDs and/or comorbid diseases in future approaches.

Pelicioni et al. [35] have reported that individuals with CND such as stroke, $\mathrm{PD}$, and MS are vulnerable to complications of illness because they did not receive the necessary care, especially during forced lockdown, in a review which is evaluating data from several countries. In addition to the results of Pelicioni et al. [35], our data indicated that the QoL was lower especially in the group with disrupted treatment.

It has been reported that living alone, a lower level of education, not having children, or having $>2$ children, living in urban areas, female gender, age, past psychiatric history, substance abuse, and poor self-care are factors associated with depression, anxiety, and stress in various studies [26, 27, 29, 35-44]. In our study, because the percentage of people living alone is low (6\%), no interpretation could be made in terms of PTSD risk. Unlike other studies, in our study, the rate of PTSD was found to be low in those living in metropolitan areas. This may be due to the fact that the participants are a group of patients whose health is already closely followed by their hospital. Considering that the epidemic first broke out in metropolitan areas, it is likely that those living in the metropolis at the time of the test had become accustomed to the pandemic processes [45]. Different results may be obtained in larger studies.

Thaller et al. [46] evaluated new-onset papilledema and those with existing idiopathic intracranial hypertension during the first national lockdown in the United Kingdom. In this study, they found an increase in the number of such patients during the quarantine period. The authors tried to explain this situation according to 
the feedback they received from the patients. They listed the possible causes of this situation as follows: quarantine-induced lifestyle changes that lead to patients' impaired access to emergency care, prolonged waiting times, hesitancy in seeking help, and weight gain. In another study, conducted in India, during the months when the COVID-19 epidemic peaked, it was reported that admissions for stroke decreased by $40 \%$ due to disruptions in medical assistance and people's fear of emergency wards [47]. In our study, the DIT ratio was found to be $32 \%$ and it was related to PTSD. Fears of going to hospital and being contaminated by COVID-19 have been reported by patients as common causes of DIT.

PTSD was reported as being $7 \%$ in the general population, but $96.2 \%$ in patients hospitalized with COVID-19 $[48,49]$. In our study, PTSD was found to be significantly higher in contact with COVID-19 patients and diagnosed with COVID-19 group. It has been reported that motor and nonmotor symptoms worsen in patients with $\mathrm{PD}$ at the beginning of the pandemic and new adjustments should be made in the treatment [50]. It has also been stated that these patients may have a high risk for COVID-19 due to their advanced age and respiratory problems. It has been stated that lockdown will cause disruption in physical exercise for these patients and that their illness will progress more rapidly [51]. In our study, PD was the eldest group. COVID-19 contact and diagnosis rates were found to be the lowest in this group where quarantine measures were strictly implemented. In addition, the WHOQOL-BREF social score and IES-R score were the lowest in this group. In terms of DIT, it ranked third after the CVD and PNP groups. Our results suggested that lockdown might prevent these people from becoming ill and posttraumatic stress. However, lockdown led to restricted social interaction.

Although headache is a common COVID-19 symptom, worsening due to pandemic-related problems has not been identified in patients with previous primary headache [52]. In addition, the negative psychological effects of lockdown have been documented as particularly affecting 18-30 year olds [53]. The HA group is one of the youngest groups in our study. For this reason, because they were the least exposed to lockdown, they had a high rate of contact with COVID-19 patients. This situation may result in an increase level of stress.

Because of its use of disease-modifying treatments, MS has become a focus of attention during the COVID-19 pandemic. MS associations and working groups have developed online follow-up programs for patients [54, 55]. It has been suggested that the rate of neuropsychiatric and cognitive impact in MS patients will increase during the pandemic [53]. In a study, it was found that younger MS patients who have lower socioeconomic levels have higher rates of exposure to COVID-19 and a higher rate of DIT [56]. In our study, the MS group was among the youngest groups. It was determined that MS patients had a high QoL and low PTSD. This result could be related to their low DIT level. In Turkey, MS outpatient clinics and the MS Society have created an intense online support program including tele-medicine for patients in some hospitals. We believe that these various services have contributed to these positive results.

An international consensus regarding epilepsy patients decided that epilepsy patients should - as far as possible - avoid hospitals holding a risk of COVID-19 transmission - and that the patients should continue their treatment at home and should be provided with a supply of regular medicines, and online follow-up programs [57, 58]. In our study, the lowest rate of DIT was found in the epilepsy group. On the other hand, the possibility of contact with COVID-19 patients and a possible diagnosis of COVID-19 and resulting stress levels were found to be high in the epilepsy group. This is due to the fact that young people are less exposed to lockdown.

Among the neurological complications of COVID-19, Guillain-Barré syndrome, Miller Fisher syndrome, and recurrence of chronic inflammatory demyelinating polyneuropathy (CIDP) have been reported [59]. One part of our PNP group consisted of CIDP patients. In these patients, the IVIG therapy was interrupted during the lockdown period because most hospitals are currently reserved for COVID-19 patients. In addition, because gabapentin and pregabalin cannot be obtained without prescription, patients had difficulty in obtaining these drugs during the lockdown.

In a review of stroke management in pandemics in Italy, France, and Germany, it was stated that the number of stroke units was reduced. The number of stroke patients admitted to emergency wards has decreased significantly because of the fear of COVID-19 [60]. In our study, we found that the CVD group had the highest rate of DIT and PTSD. Physical disability and fear of going to hospital may be the cause of higher DIT and PTSD ratios in these patients.

There are certain limitations to this study - patients were not evaluated in detail in terms of depression and anxiety according to the severity of the disease. In addition, the size of the study group is small. Some neurological diseases, such as motor neurons, neuromuscular junction, and muscle disease, could not be included in this study because their rate of respiratory complications 
is higher than in other groups. Patients with dementia were not included in this study, as these patients would be unable to deal appropriately with the questions.

The forms used in our study were filled out by patients after a face-to-face meeting with their physician in an outpatient clinic. This can be an advantage for our study because this method may motivate the patients to more easily focus on the questions and to fully complete all questionnaires.

In conclusion, lockdown is protective against COVID-19 spread. However, it can increase stress in some disease groups. To our knowledge, our study is the first to evaluate the results of chronic neurological patients' exposure to lockdown. The focus on QoL in these patients is aimed at determining the extent of posttraumatic stress and disruption in their treatment. The results have enabled us to obtain information about the needs of patients during lockdown. It is necessary to develop strategies to reduce the burden of stress for every age-group and every disease group over the lockdown period. We hope our results and the light they shed on the current situation will also be useful for future studies.

\section{Acknowledgements}

The authors would like to thank the neurologists from all over Turkey who participated in data collection. We also thank the Turkish Neurology Society for encouraging us to carry out this study.

\section{Statement of Ethics}

The study received approval from the Ministry of Health (Confirmation No: 2020-05-14T12_41_06). The study protocol was approved by the local Ethics Committee of the Maltepe University (Acceptance No: 2020/900/55). Also, written informed consent was obtained from all patients for use of clinical data in research.

\section{Conflict of Interest Statement}

The authors declare that there is no conflict of interest.

\section{Funding Sources}

The authors received no funding for this work.

\section{Author Contributions}

1. Sevki Sahin is a member of the Turkish Neurology SocietyCOVID-19 \& Neurology Study Group.

2. Study design and concept: Sevki Sahin, Sibel Karsidag, Nilgun Cinar, and Miruna Florentina Ates.

3. Acquisition of the data: Sevki Sahin, Sibel Karsidag, Nilgun Cinar, Miruna Florentina Ates, Serkan Demir, Fettah Eren, Abdurrahman Neyal, Aysin Kisabay Ak, Ayse Bora Tokcaer, Esra Erkoç Ataoglu, Seda Nur Akkaya, Esra Aciman Demirel, Filiz Koc, Serefnur Ozturk, Yasemin Ekmekyapar Firat, Tugba Okluoglu, Erdem Togrol, Ali Kemal Erdemoglu, Nesrin Ergin, Refah Sayın, Aysegul Demir, and Süeda Ecem Yılmaz.

4. Data analysis and interpretation: Sevki Sahin and Sibel Karsidag.

5. Manuscript preparation and revision: Sevki Sahin and Sibel Karsidag.

\section{References}

1 Guan WJ, Ni ZY, Hu Y, Liang WH, Ou CQ, $\mathrm{He}$ JX, et al. Clinical characteristics of Coronavirus Disease 2019 in China. N Engl J Med. 2020;382(18):1708-20.

2 World Health Organization. Novel Coronavirus (2019-nCoV): situation report, 22. World Health Organization; 2020.

3 Coronaviridae Study Group of the International Committee on Taxonomy of Viruses. The species Severe acute respiratory syndrome-related coronavirus: classifying 2019-nCoV and naming it SARS-CoV-2. Nat Microbiol. 2020;5(4):536-44.

4 Wilder-Smith A, Chiew CJ, Lee VJ. Can we contain the covid-19 outbreak with the same measures as for SARS? Lancet Infect Dis. 2020;20(5):e102-7.

5 Graham RL, Donaldson EF, Baric RS. A decade after SARS: strategies for controlling emerging coronaviruses. Nat Rev Microbiol. 2013;11:836-48.

6 Brooks SK, Webster RK, Smith LE, Woodland L, Wessely S, Greenberg N, et al. The psychological impact of quarantine and how to reduce it: rapid review of the evidence. Lancet. 2020;395(395):912-20.
7 Denes A, Gumel AB. Modeling the impact of quarantine during an outbreak of Ebola virüs disease. Infect Dis Model. 2019;4:12-27.

8 Lau JT, Yang X, Pang E, Tsui HY, Wong E, Wing YK. SARS-related perceptions in Hong Kong. Emerg Infect Dis. 2005;11:417-24.

9 Monteith LL, Holliday R, Brown TL, Brenner LA, Mohatt NV. Preventing suicide in rural communities during the COVID-19 pandemic. J Rural Health. 2021;37(1):179-84.

10 Rubin GJ, Wessely S. The psychological effects of quarantining a city. BMJ. 2020;368:m313.

11 Reynolds DL, Garay JR, Deamond SL, Moran MK, Gold W, Styra R. Understanding, compliance and psychological impact of the SARS quarantine experience. Epidemiol Infect. 2008; 136:997.

12 Weiss DS, Marmar CR. The impact of event scale-revised. In: Wilson JP, Keane TM, editors. Assessing psychological trauma and PTSD. New York: Guilford Press; 1997. p. 399-411.

13 Rash CJ, Coffey SF, Baschnagel JS, Drobes DJ, Saladin ME. Psychometric properties of the IES- $R$ in traumatized substance dependent individuals with and without PTSD. Addict Behav. 2008;33:1039-47.
14 Asukai N, Kato H, Kawamura N, Kim Y, Yamamoto K, Kishimoto J, et al. Reliability and validity of the Japanese-language version of the Impact of Event Scale-revised (IES-R-J): four studies of different traumatic events. J Nerv Ment Dis. 2002;190:175-82.

15 Creamer M, Bell R, Failla S. Psychometric properties of the Impact of Event Scale: revised. Behav Res Ther. 2003;41(12):1489-96.

16 Çorapçıŏlu A, Yargıç İ, Geyran P, Kocabaşoğlu N. Olayların Etkisi Ölçeği” (IES-R) Türkçe Versiyonunun Geçerlilik ve Güvenilirliği. New/Yeni Symp J. 2006;44(1):14-22.

17 Vanaken L, Scheveneels S, Belmans E, Hermans D. Validation of the impact of event scale with modifications for COVID-19 (IESCOVID19). Front Psychiatry. 2020;11(11): 738 .

18 The WHOQOL Group. Development of the World Health Organization WHOQOLBREF quality of life assessment. Psychol Med. 1998;28(3):551-8.

19 Eser E, Fidnner H, Fidaner C, Eser SY, Elbi H, Göker E. WHOQOL-100 ve WHOQOLBREF'in psikometrik özellikleri. Türk Psikiyatri Derg. 2010;21(1):37-48. 
20 Guo YR, Cao QD, Hong ZS, Tan YY, Chen $\mathrm{SD}$, Jin $\mathrm{HJ}$, et al. The origin, transmission and clinical therapies on coronavirus disease 2019 (COVID-19) outbreak: an update on the status. Mil Med Res. 2020 13;7(1):11.

21 Maunder R, Hunter J, Vincent L, Bennett J, Peladeau N, Leszcz M, et al. The immediate psychological and occupational impact of the 2003 SARS outbreak in a teaching hospital. CMAJ. 2003; 168:1245.

22 Hawryluck L, Gold WL, Robinson S, Pogorski S, Galea S, Styra R. SARS control and psychological effects of quarantine, Toronto, Canada. Emerg Infect Dis. 2004;10:1206.

23 Leung GM, Lam TH, Ho LM, Ho SY, Chan $\mathrm{BH}$, Wong IO, et al. The impact of community psychological responses on outbreak control for severe acute respiratory syndrome in Hong Kong. J Epidemiol Community Health. 2003;57(11):857-63.

24 Shultz JM, Cooper JL, Baingana F, Oquendo MA, Espinel Z, Althouse BM, et al. The role of fear-related behaviors in the 2013-2016 West Africa ebola virus disease outbreak. Curr Psychiatry Rep. 2016;18(11):104.

25 Al-Mohrej OA, Al-Shirian SD, Al-Otaibi SK, Tamim HM, Masuadi EM, Fakhoury HM. Is the Saudi public aware of Middle East respiratory syndrome? J Infect Public Health. 2016; 9(3):259-66.

26 Zhang Y, Ma ZF. Impact of the COVID-19 pandemic on mental health and quality of life among local residents in Liaoning Province, China: a cross-sectional study. Int J Environ Res Public Health. 2020;17(7):2381.

27 Wang C, Pan R, Wan X, Tan Y, Xu L, Ho CS, et al. Immediate psychological responses and associated factors during the initial stage of the 2019 coronavirus disease (COVID-19) epidemic among the general population in China. Int J Environ Res Public Health. 2020; 17(5):1729.

28 Losada-Baltar A, Márquez-González M, Jiménez-Gonzalo L, Pedroso-Chaparro MDS, Gallego-Alberto L, Fernandes-Pires J. [Differences in anxiety, sadness, loneliness and comorbid anxiety and sadness as a function of age and self-perceptions of aging during the lock-out period due to COVID-19]. Rev Esp Geriatr Gerontol. 2020;55(5):272-8.

29 Wang C, Pan R, Wan X, Tan Y, Xu L, McIntyre RS, et al. A longitudinal study on the mental health of general population during the COVID-19 epidemic in China. Brain Behav Immun. 2020;87:40-8.

30 Huang Y, Zhao N. Chinese mental health burden during the COVID-19 pandemic. Asian J Psychiatr. 2020;51:102052.

31 Epifanio MS, Andrei F, Mancini G, Agostini F, Piombo MA, Spicuzza V, et al. The impact of COVID-19 pandemic and lockdown measures on quality of life among Italian general population. J Clin Med. 2021;10(2):289.

32 Muris P, Field AP. The role of verbal threat information in the development of childhood fear. "Beware the Jabberwock!". Clin Child Fam Psychol Rev. 2010;13:129.
33 Dubey S, Dubey MJ, Ghosh R, Chatterjee S. Children of frontline COVID-19 warriors: our observations. J Pediatr. 2020;224:188-9.

34 Li Q, Guan X, Wu P, Wang X, Zhou L, Tong $\mathrm{Y}$, et al. Early transmission dynamics in $\mathrm{Wu}-$ han, China, of novel coronavirus-infected pneumonia. N Engl J Med. 2020;382: $1199 \mathrm{e} 207$.

35 Pelicioni PHS, Schulz-Moore JS, Hale L, Canning CG, Lord SR. Lockdown during COVID-19 and the increase of frailty in people with neurological conditions. Front Neurol. 2020;11(11):604299.

36 Dubey S, Biswas P, Ghosh R, Chatterjee S, Dubey MJ, Chatterjee S, et al. Psychosocial impact of COVID-19. Diabetes Metab Syndr. 2020;14(5):779-88.

37 Cao W, Fang Z, Hou G, Han M, Xu X, Dong $\mathrm{J}$, et al. The psychological impact of the COVID-19 epidemic on college students in China. Psychiatry Res. 2020;287:112934.

38 Gao J, Zheng P, Jia Y, Chen H, Mao Y, Chen $S$, et al. Mental health problems and social media exposure during COVID-19 outbreak. PLoS One. 2020;15(4):e0231924.

39 Mazza C, Ricci E, Biondi S, Colasanti M, Ferracuti S, Napoli C, et al. A Nationwide survey of psychological distress among Italian people during the COVID-19 Pandemic: immediate psychological responses and associated factors. Int J Environ Res Public Health. 2020; 17(9):3165.

40 Lai J, Ma S, Wang Y, Cai Z, Hu J, Wei N, et al. Factors associated with mental health outcomes among health care workers exposed to Coronavirus Disease 2019. JAMA Netw Open. 2020;3(3):e203976.

41 Ozdin S, Bayrak Ozdin S. Levels and predictors of anxiety, depression and health anxiety during COVID-19 pandemic in Turkish society: the importance of gender. Int J Soc Psychiatry. 2020;66(5):504-11.

42 Huang J, Liu F, Teng Z, Chen J, Zhao J, Wang $\mathrm{X}$, et al. Care for the psychological status of frontline medical staff fighting against $\mathrm{CO}$ VID-19. Clin Infect Dis. 2020; 15;71(12): 3268-9.

43 Du J, Dong L, Wang T, Yuan C, Fu R, Zhang $\mathrm{L}$, et al. Psychological symptoms among frontline healthcare workers during $\mathrm{CO}$ VID-19 outbreak in Wuhan. Gen Hosp Psychiatry. 2020;67:144-5.

44 Mo Y, Deng L, Zhang L, Lang Q, Liao C, Wang $N$, et al. Work stress among Chinese nurses to support Wuhan for fighting against the COVID-19 epidemic. J Nurs Manag. 2020;28(5):1002-9.

45 Litman T. Lessons from pandemics: comparing urban and rural risks; 2020. Available from: https://www.planetizen.com/blogs/109051lessons-pandemics-comparing-urban-and-rural-risks Accessed 2020 Apr 14.

46 Thaller M, Tsermoulas G, Sun R, Mollan SP, Sinclair AJ. Negative impact of COVID-19 lockdown on papilloedema and idiopathic intracranial hypertension. J Neurol Neurosurg Psychiatry. 2021;92(7):795-97.
47 Sylaja PN, Srivastava MVP, Shah S, Bhatia R, Khurana D, Sharma A, et al. The SARSCoV-2/COVID-19 pandemic and challenges in stroke care in India. Ann N Y Acad Sci. 2020;1473(1):3-10.

48 Liu N, Zhang F, Wei C, Jia Y, Shang Z, Sun L, et al. Prevalence and predictors of PTSS during COVID-19 outbreak in China hardest-hit areas: gender differences matter. Psychiatry Res. 2020;287:112921.

49 Bo HX, Li W, Yang Y, Wang Y, Zhang Q, Cheung T, et al. Posttraumatic stress symptoms and attitude toward crisis mental health services among clinically stable patients with COVID-19 in China. Psychol Med. 2020;27: $1-2$.

50 Cilia R, Bonvegna S, Straccia G, Andreasi NG, Elia AE, Romito LM, et al. Effects of COVID-19 on Parkinson's disease clinical features: a community-based case-control study. Mov Disord. 2020;35(8):1287-92.

51 Helmich RC, Bloem BR. The Impact of the COVID-19 pandemic on Parkinson's Disease: hidden sorrows and emerging opportunities. J Parkinsons Dis. 2020;10(2):351-4.

52 Uygun Ö, Ertaş M, Ekizoğlu E, Bolay H, Özge A, Kocasoy Orhan E, et al. Headache characteristics in COVID-19 pandemic: a survey study. J Headache Pain. 2020;21(1):121.

53 Pandey D, Bansal S, Goyal S, Garg A, Sethi N, Pothiyill DI, et al. Psychological impact of mass quarantine on population during pandemics: the COVID-19 Lock - Down (COLD) study. PLoS One. 2020;15(10): e0240501.

54 Sormani MP. Italian Study Group on COVID-19 infection in multiple sclerosis. An Italian programme for COVID-19 infection in multiple sclerosis. Lancet Neurol. 2020; 19(6):481-2.

55 Haji Akhoundi F, Sahraian MA, Naser Moghadasi A. Neuropsychiatric and cognitive effects of the COVID-19 outbreak on multiple sclerosis patients. Mult Scler Relat Disord. 2020;41:102164.

56 Moss BP, Mahajan KR, Bermel RA, Hellisz K, Hua LH, Hudec T, et al. Multiple sclerosis management during the COVID-19 pandemic. Mult Scler. 2020;26(10):1163-71.

57 French JA, Brodie MJ, Caraballo R, Devinsky O, Ding D, Jehi L, et al. Keeping people with epilepsy safe during the COVID-19 pandemic. Neurology. 2020; 9;94(23):1032-7.

58 Adan GH, Mitchell JW, Marson T. Epilepsy care in the COVID-19 era. Clin Med. 2020; 20(4):e104-6.

59 Munhoz RP, Pedroso JL, Nascimento FA, Almeida SM, Barsottini OGP, Cardoso FEC, et al. Neurological complications in patients with SARS-CoV-2 infection: a systematic review. Arq Neuropsiquiatr. 2020;78(5):290300

60 Bersano A, Kraemer M, Touzé E, Weber R, Alamowitch S, Sibon I, et al. Stroke care during the COVID-19 pandemic: experience from three large European countries. Eur J Neurol. 2020;27(9):1794-800. 